\title{
SEDIMENT FLUSHING FOR STEEP SLOPE RESERVOIR
}

\author{
M.N. MD. NOH ${ }^{1}$, Masanori MICHIUE ${ }^{2}$, Osamu HINOKIDANI ${ }^{3}$ and Takahito TSUJI ${ }^{4}$ \\ ${ }^{1,4}$ Student Member of JSCE, Graduate Students \\ ${ }^{2}$ Fellow of JSCE, Dr. of Eng., Professor \\ ${ }^{3}$ Member of JSCE, Dr. of Eng., Associate Professor \\ Department of Civil Engineering, Tottori University, (Tottori-shi, Koyama-cho Minami 4-101, 680-8552 Japan)
}

\begin{abstract}
This study attempts to investigate the practicality of utilizing the upstream Froude number in determining the sediment flushing performance through a sluice gate within the scope of onedimensional sediment flushing model for a steep slope reservoir. Herewith, the study contemplates on the effect of the width ratio $C_{b}$, length of sub-critical zone $x$ and sequent depth of hydraulic jump $h_{d}$ in determining the flushing performance. Accordingly, the flushing performance line can be visualized easily when the combinations of the above parameters are compared to the upstream Froude number $F_{u p}$. The previous results indicate that the flushing performance behaves non-linearly for Froude number below 4.0 under both the fixed bed and movable bed categories. Under the current study however, as the Froude number increases more than 4.0, the flushing performance line has been discovered to become constant. Furthermore, a rebound curve could be visualized when Froude number is between 3.5 4.0.
\end{abstract}

Key Words: Flushing performance, steep slope reservoir and sluice gate

\section{INTRODUCTION}

Sediment management for a certain type of reservoir is a compulsory operation especially when the amounts of sediments have reached maximum storage capacity. For a hydropower generation scheme this type of operation is a vital maintenance work so that excess sediments can be avoided from entering the turbine compartment i.e. overflow of sediments from sand trap. Without proper sediment removal measures, the electricity generation could be disrupted from time to time. Therefore, it is common to find that human labor being employed to remove the sediments accumulated inside the trap area. In the long run this technique is costly due to the high labor cost.

The flushing technique proposes under this study should be able to aid design engineers in determining a suitable gate sizes especially for newly constructed structure. For existing structure, the engineers will find it handy in enhancing their ability to perform proper sediment flushing operation. With this, the most economical design as well as the most suitable gate opening height can be calculated and operated easily. For normal type of reservoir, this technique is applicable for any reservoir located along a mountain stream that is also associated with the occurrence of hydraulic jump. Accordingly, this technique will aid the engineers and even scientists to figure out whether or not the incoming discharge will actually fall into a good or poor flushing criterion.

\section{BACKGROUND AND OBJECTIVE}

Fig. 1 portrays the general outline of flushing process investigated under this study. From this 
figure, one can easily see from the top left figure (under the most conservative case $\mathrm{C}_{\mathrm{b}}=1.0$ with high gate opening height), any sediment being fed inside the flume will be flushed out all the way through without any obstruction. This is logical since the supercritical flow along the flume will be able to flush out the sediments away at high speed. But once a smaller $C_{b}$ with lower ' $a$ ' being set up inside the flume (Fig. 1 top right), obviously two flow regions will appear. The upstream will be supercritical while just behind the gate will be subcritical with a hydraulic jump in these flow regions. If any sediment is released inside the flume, definitely a deposition will occur.

The figure at the bottom left shows a simple sketch of the initial stage of flushing. As the gate is opened higher such that the water level will drop, the sediments inside the impounded area will start to move out. Identical to the flow profile, the flushing shape becomes parallel to the bed. Finally, the figure at the bottom right shows the sketch of final stage of flushing. Obviously, the hydraulic jump has moved near the gate vicinity while the water surface profile becomes flat. The amount of sediments remain behind the gate also decrease substantially.

In order to verify these phenomena, the study had opted for two types of experiments. The first type was conducted under fixed bed while the second type was for movable bed. For the case of fixed bed, the experiment was conducted by releasing sands directly from the upstream of hydraulic jump. By doing so, the good flushing performance was defined when $95 \%$ or more sands could move out of the gate. On the other hand, in the movable bed study, the sediments were allowed to deposit inside the flume. Flushing would be done once the deposited sediments moved near the gate vicinity. Under this case, good flushing condition was defined if $80 \%$ or more flushing could be achieved. This percentage is taken by dividing the volume of sediment flushed out over the volume of water recorded at the final stage of flushing.

By these definitions, for the case of fixed bed, the flushing performance line was found to vary non-linearly as shown in Fig. 2. As stated in the results $^{3)}$, this line could be deduced as

$$
C_{b} x / h_{d} \leq 50 F_{u p}^{-2.25}
$$

Where $\mathrm{C}_{\mathrm{b}}$ : ratio of gate width to flume width, $\mathrm{x}$ :

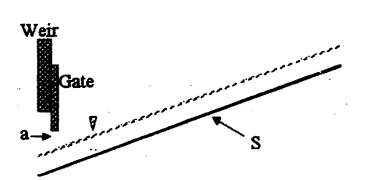

$\mathrm{C}_{\mathrm{b}}=1.0$ with high $\mathrm{a}$

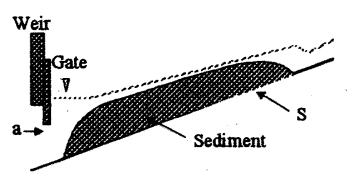

Initial Flushing Stage

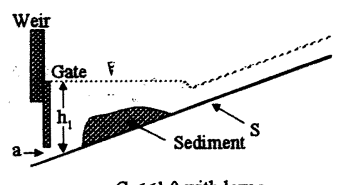

$\mathrm{C}_{\mathrm{b}} \ll<1.0$ with low a

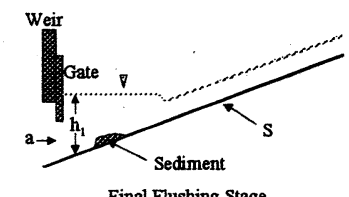

Final Flushing Stage

Fig. 1: Flushing Process

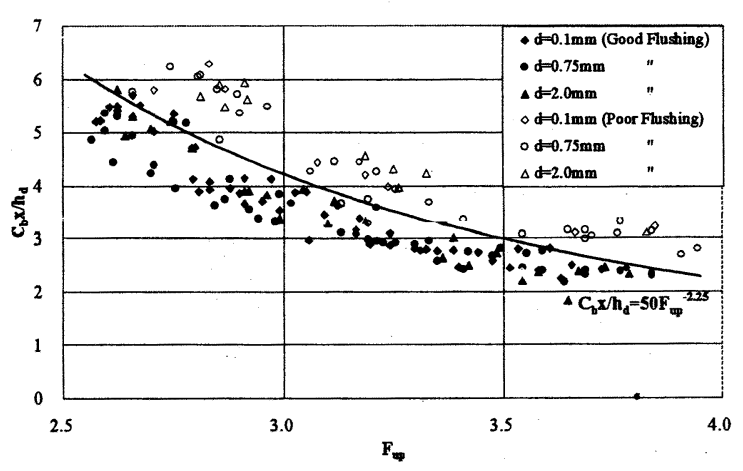

Fig. 2: Flushing Performance (Fixed Bed)

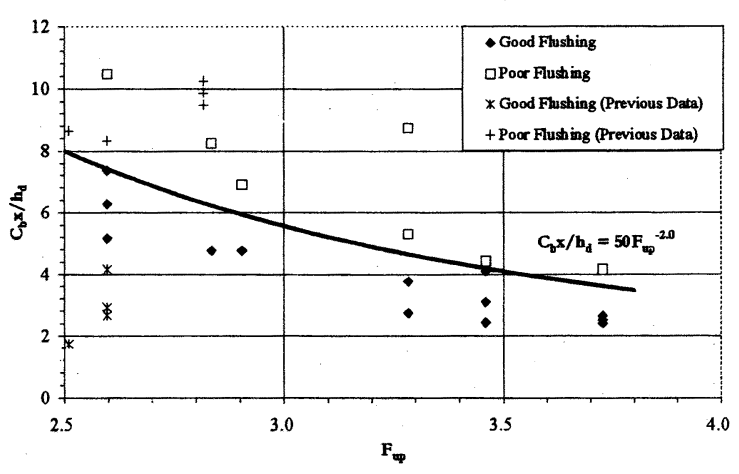

Fig. 3: Flushing Performance (Movable Bed)

length of sub-critical zone including the length of hydraulic jump, $h_{d}$ : sequent depth of hydraulic jump and $F_{\text {up: }}$ upstream Froude number. Fig. 2 also shows that the effect of grain size is small for this kind of flow condition ( $\mathrm{d}$ between $0.1 \sim 2.0 \mathrm{~mm}$ ). This is logical since the hydraulic jump and the suction force that lingers at the gate vicinity are able to churn and pull the sediments out of the sub-critical zone area. Apparently, the grain sizes had been observed to affect the time taken for flushing rather than the flushing performance.

For the case of movable bed category, as 
anticipated, the same trend had been observed with the flushing line moved slightly higher than before. Fig. 3 shows the outcome of this investigation ${ }^{2}$. Apparently, the flushing performance line could be written as

$$
C_{b} x / h_{d} \leq 50 F_{u p}^{-2.0}
$$

The differences between the two categories only located at the power factor, which decreased from 2.25 to 2.0. As to ease the estimation of certain dubious parameters, the previous study also opted to explore the discharge coefficient $\mathrm{C}_{\mathrm{a}}$, length of subcritical zone $x$ and length of suction $x_{1}$. Fig. 4 to 6 depicts the outcome. Then, Eq. 3 to 5 lists down the equations ${ }^{3)}$

$$
\begin{gathered}
C_{a}=\left\{\log \left(\frac{h_{1}}{a}+0.3\right)\right\}^{0.1}-0.38 \\
x=\frac{1}{S}\left(h_{1}-\frac{\sqrt{1+8 F_{u p}^{2}}-1}{2} h_{u p}\right) \\
x_{l}=16 C_{b} \frac{a}{h_{1}} S x
\end{gathered}
$$

Where $C_{a}$ : discharge coefficient, $h_{1}$ : water depth in the vicinity of the gate, $a$ : gate opening height, $S$ : bed slope and $x_{1}$ : length of suction. The values of $h_{1}$ and $h_{\mathrm{up}}$ can be estimated by the following equations.

$$
\begin{aligned}
& h_{1}=\frac{1}{2 g}\left(\frac{Q}{C_{a} a b}\right) \\
& h_{u p}=\left(\frac{n Q}{B S^{1 / 2}}\right)^{3 / 5}
\end{aligned}
$$

Where Q: discharge, b: gate width and B: flume width. Eq. 7 is also useful in order to get the value of $F_{\text {up }}$. In determining the value of $h_{1}$, a trial and error procedure between Eq. 3 and 6 has to be performed.

As to investigate further the variation of flushing performance line towards the Froude number, in the present study a higher Froude number had been imposed. With this, it will be shown later that the variation move towards a constant value. Moreover, a transition zone can be detected when Froude number is located between 3.5 4.0.

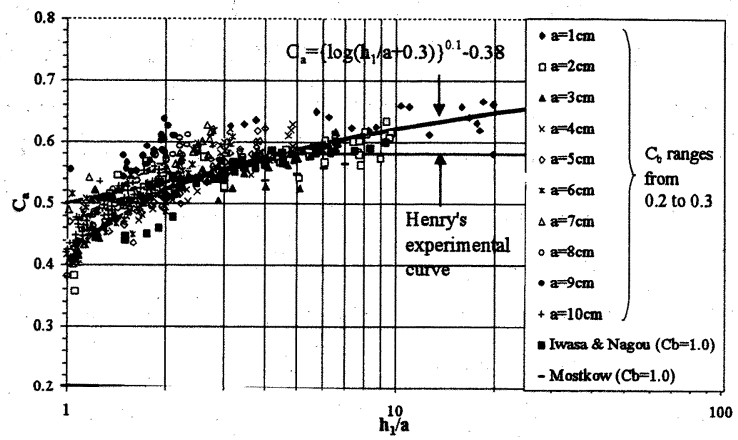

Fig. 4: Discharge Coefficient

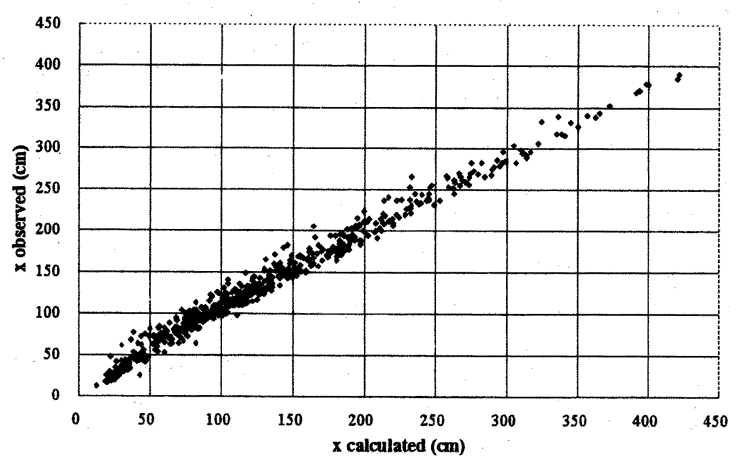

Fig. 5: Length $x$

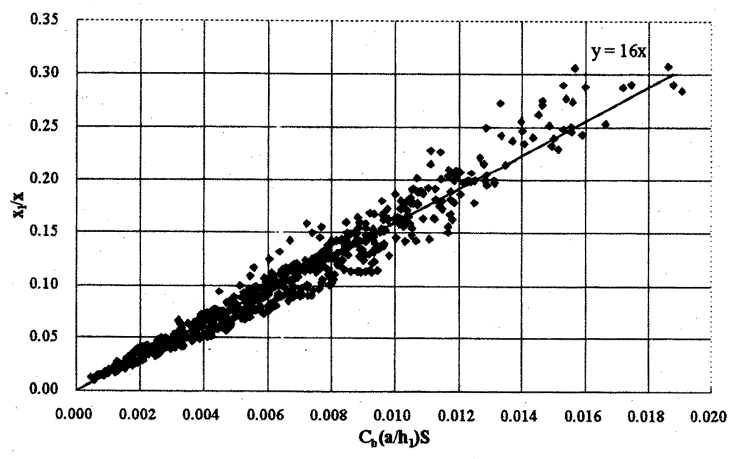

Fig. 6: Length of Suction

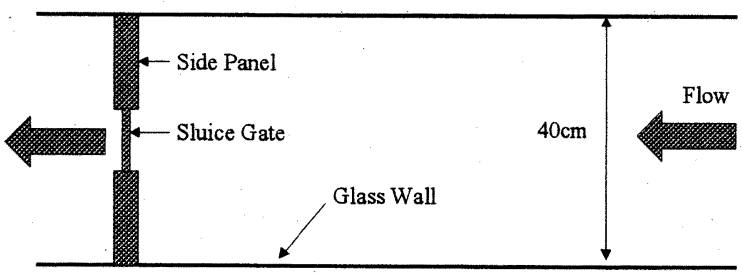

Fig. 7: Plan View of Experiment Setup

\section{EXPERIMENT SETUP \& PROCEDURE}

Fig. 7 indicates the plan view of the current study. A $40 \mathrm{~cm}$ flume was used with the gate materials were made of acrylics. For the case of 
fixed bed, 3 types of bed slopes $(1 / 15,1 / 20$ and $1 / 25)$ with two types of bed width (10 and $12 \mathrm{~cm})$ had been set up. Only $0.75 \mathrm{~mm}$ sand diameter with the amount of $50 \mathrm{ml}$ was utilized throughout the experiment. For each case, only one gate opening height had been imposed. Under the same discharge, if the results gave good flushing criteria, then the gate would be lowered a little and the same procedure would be commenced. This technique would be resumed until poor flushing had been observed. With the occurrence of poor flushing stage, then a new discharge would be set up.

For the case of movable bed, only $10 \mathrm{~cm}$ bed width with $1 / 15$ bed slope had been imposed with 110 liters of sand was used for each case. The sedimentation process was done by feeding into the flume 5 liters of sand at a rate of 2.5 minutes until the total volume reached 110 liters. After the deposition had moved near the gate vicinity, the gate would be opened for flushing. For measurement, the gate would be closed at any interested time frame before being opened again. In total, 14 cases had been conducted.

\section{RESULTS}

Table 1 shows the summary of experiment data for the fixed bed while Table 2 shows the summary for movable bed. Fig. 8 shows the flow patterns. Two types of flow patterns i.e. symmetrical and non-symmetrical flows occur during the flushing process. It had been indicated in the previous study (Froude number less than 4.0) that under the fixed bed category, the symmetrical flow pattern induced good flushing performance while non-symmetrical flow pattern initiated poor flushing performance. This is logical since the amount of sand used was only $50 \mathrm{ml}$; thus, this small amount of sand definitely would not affect the flow formation. Apparently, if the flow is symmetrical i.e. shorter length $\mathrm{x}$ and lower $\mathrm{h}_{1}$, then the probability for the sediments to achieve $100 \%$ flushing is high. On the other hand, non-symmetrical flow pattern also occurs especially when the gate is lowered down. With this, the water depth becomes higher while the length $\mathrm{x}$ becomes longer. According to this flow pattern, the flow will tend to move the sediments away from the gate outlet; thus, the probability of the sediments to enter the suction zone is low.

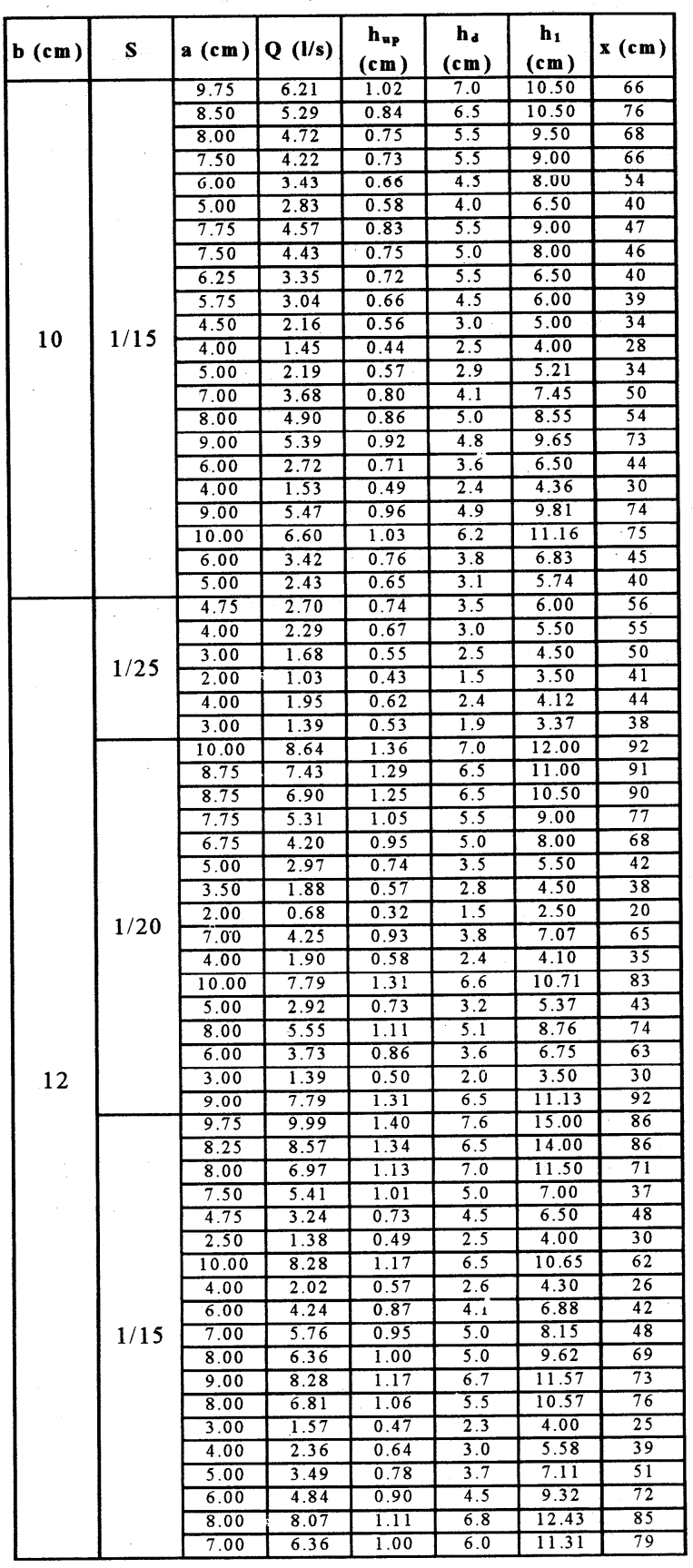

Table 1: Experiment Data for Fixed Bed

\begin{tabular}{|c|c|c|c|c|c|c|c|c|c|}
\hline \multicolumn{10}{|c|}{ Initial Vd. of Sand $=110$ liter } \\
\hline Case & $Q(/ s)$ & $a(\mathrm{~cm})$ & $h_{1}(\mathrm{~cm})$ & $\mathbf{s}$ & $\begin{array}{l}\text { Final Vd of } \\
\text { Sand (liter) }\end{array}$ & $\begin{array}{l}\text { Initial Flow } \\
\text { Pattern }\end{array}$ & $\begin{array}{l}\text { Fral Fow } \\
\text { Pattern }\end{array}$ & $\begin{array}{c}\text { Bed } \\
\text { Pattern }\end{array}$ & \begin{tabular}{|c|} 
Flushing \\
Performanof
\end{tabular} \\
\hline $7-1$ & 3.88 & 7.5 & 6.27 & $\mathrm{~V} / 15$ & $\begin{array}{ll}0.18 \\
\end{array}$ & $\mathrm{~s}$ & $\mathrm{~s}$ & $\mathrm{~A}$ & \begin{tabular}{|l|} 
good \\
\end{tabular} \\
\hline $7-2$ & 3.97 & 7.0 & 8.95 & $\mathrm{D} / 15$ & 0.35 & NS & NS & $\mathrm{C}$ & good \\
\hline $7-3$ & 3.42 & 6.5 & 6.01 & $\mathrm{~V} / 15$ & 0.35 & $s$ & $\mathrm{~s}$ & $\mathrm{~A}$ & good \\
\hline $7-4$ & 3.86 & 6.0 & 9.42 & $1 / 15$ & 1.10 & NS & $\mathrm{NS}$ & $\mathrm{C}$ & good \\
\hline $7-5$ & 3.95 & 5.0 & 11.68 & $1 / 15$ & 12.60 & NS & NS & D & poor \\
\hline $8-1$ & 5.07 & 8.0 & 7.30 & $1 / 15$ & 0.12 & $\mathrm{~S}$ & $\mathrm{~s}$ & $\mathrm{~A}$ & good \\
\hline 82 & 5.04 & 7.5 & 9.48 & $1 / 15$ & 1.20 & NS & NS & $\mathrm{C}$ & good \\
\hline 83 & 5.01 & 7.0 & 10.74 & $1 / 15$ & 2.00 & NS & NS & $\mathrm{C}$ & good \\
\hline 84 & 5.13 & 6.0 & 11.43 & $1 / 15$ & 8.60 & NS & $\mathrm{s}$ & B & poor \\
\hline $9-1$ & 6.13 & 8.5 & 8.92 & $1 / 15$ & 0.23 & NS & NS & $\mathrm{C}$ & good \\
\hline $9-2$ & 6.01 & 8.0 & 11.69 & $1 / 15$ & 0.12 & $\mathrm{NS}$ & NS & $\mathrm{C}$ & good \\
\hline $9-3$ & 6.12 & 9.5 & 9.87 & $1 / 15$ & 0.40 & NS & NS & $\mathrm{C}$ & good \\
\hline 94 & 5.91 & 7.5 & 12.23 & $1 / 15$ & 3.00 & NS & NS & $\mathrm{C}$ & good \\
\hline 9.5 & 5.85 & 6.5 & 12.87 & $1 / 15$ & 9.10 & NS & NS & $\mathrm{D}$ & poor \\
\hline
\end{tabular}

Table 2: Experiment Data for Movable Bed 
For movable bed category, the previous results indicate that even under non-symmetrical flow pattern, good flushing performance could be achieved. Fig. 9 shows the final bed formation. Type A and B should infer to the bed formation governed under symmetrical flow while type $\mathrm{C}$ and D for non-symmetrical flow. From Fig. 9 also the bed formation between good and poor flushing criteria can be easily justified. Good flushing performance should be related to the occurrence of flushing channel at the end of flushing session while poor flushing performance should incur the opposite phenomena.

\section{(1) Fixed Bed}

The results for this category are shown in Fig. 10 and 11 . The results have been combined with the previous data so that the entire range of Froude number between $2.5 \sim 6.0$ could be depicted. Fig. 10 shows the results for good flushing performance only. The effect of gate geometry also is neglected. Meanwhile Fig. 11 includes the effect of gate geometry as well as the good and the poor flushing data. The flow patterns are also inserted for proper understanding. From both figures, it can be observed easily that the effect of geometry becomes small as the Froude number moves higher than 3.5. In addition, the flushing performance line starts to intrude inside the non-symmetrical flow area once the Froude number reaches more than 3.5.

\section{(2) Movable Bed}

The outcomes for these results is shown in Fig. 12. Identical to case of fixed bed, the flushing pcrformance line interestingly becomes constant as the Froude number reaches 4.0 onwards. Unlike the case of fixed bed, a transition zone could be justified to occur between 3.5 4.0.

\section{DISCUSSION}

The current results contemplate on the variation of flushing performance line towards a higher range of Froude numbers. Both the fixed bed and the flexible bed results conclude that the flushing performance line varies constantly as the Froude number increases more than 4.0; thus, becomes independent of the Froude number itself. Furthermore, the effect of the gate geometry

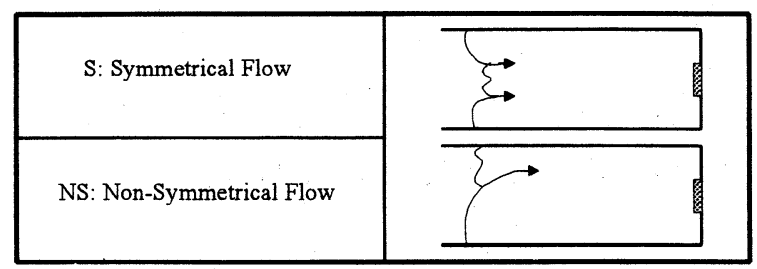

Fig. 8: Flow Patterns
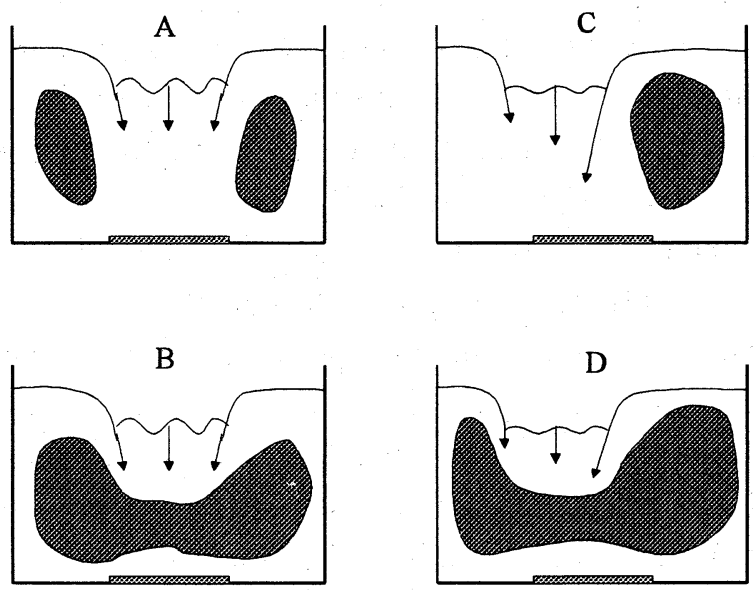

Fig. 9: Final Bed Formation

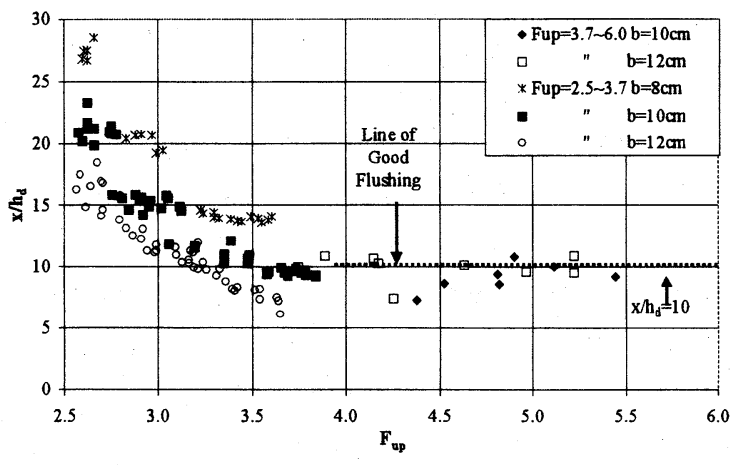

Fig. 10: Good Flushing Performance

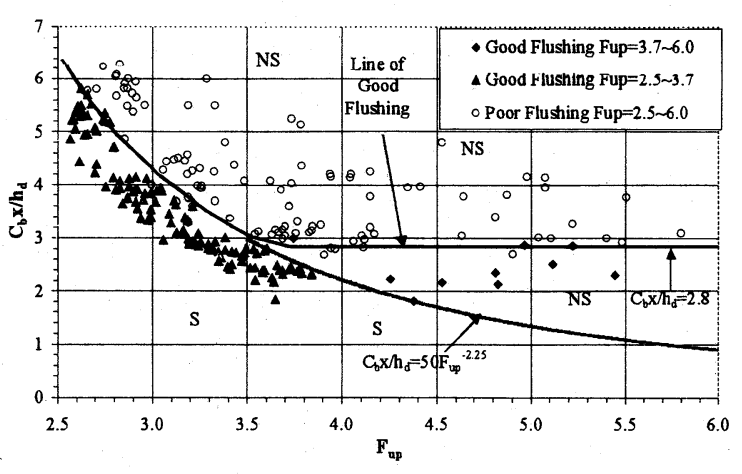

Fig. 11: Flushing Performance

becomes negligible. Fig. 13 compiles the overall results. With this it can be summarized that for Froude number more than 4.0 , the good flushing performance for the movable bed category will 
occur if

$$
C_{b} x / h_{d} \leq 2.8
$$

And for the case of fixed bed becomes

$$
C_{b} x / h_{d} \leq 5
$$

In terms of flow patterns, it can be seen that good flushing performance will occur under symmetrical flow pattern. While for the case of nonsymmetrical flow, good flushing performance will occur at certain condition, which is related to the value of $C_{b} x / h_{d}$ towards the $F_{u p}$. This is also true if one refer to the case of fixed bed and movable bed.

It is also interesting to note that the values of shear stresses recorded at the position of the sequent depth of hydraulic jump $h_{d}$ were equal or more than the critical shear stress. Therefore, in order to make full use of the current model, another condition should be satisfied as indicated by Eq. 10

$$
\tau_{* h_{d}} \geq \tau_{*_{c}}
$$

\section{CONCLUSIONS}

The flushing performance line can be categorized as a tool to identify between the good and the poor flushing conditions. The application of this line is convenient to be used especially to determine the gate sizes as well as getting the appropriate gate opening height to be set up during any sediment flushing assignment. The application of this line should be governed within steep slope reservoir that can be defined as a one-dimensional flow associated with hydraulic jump.

In applying the above methodology, it should be reminded that all the supplementary equations $(\mathrm{Eq}$. 3 to 6) were empirically derived for clear water condition. Therefore, the users should note that the values obtained indicate the final stage of flushing where the amount of sediments inside the flume is minimum. Furthermore, these equations also are useful to determine the initial condition before any sediments being released inside the reservoir. Practically speaking, for any sediment flushing assignments, the final outcomes are the most anticipated by any engineers. Thus, these equations actually enhance the current model by enabling one to forecast the final condition.

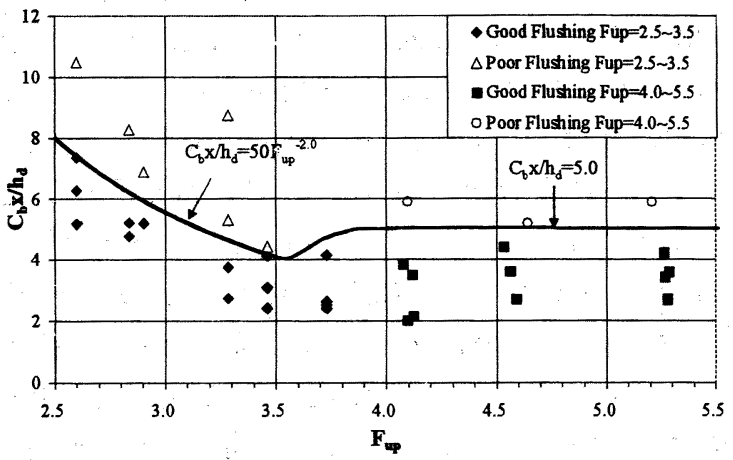

Fig. 12: Flushing Performance

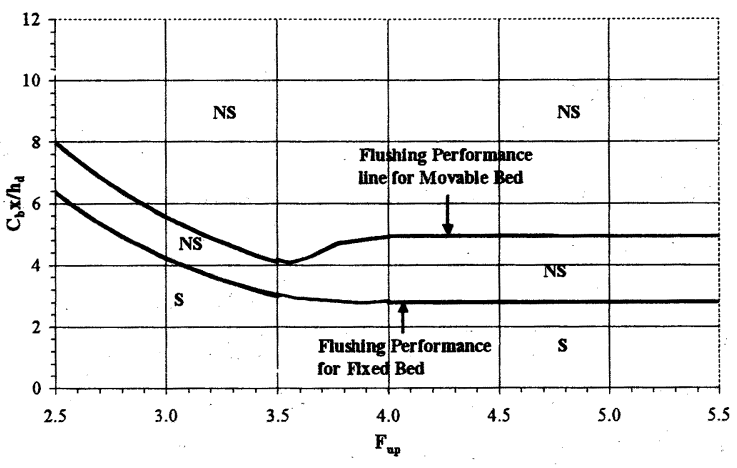

Fig. 13: Flushing Performance

ACKNOWLEDGEMENT: High appreciation is forwarded towards Mr. T. Oda, Mr. T. Hara and Ms. $R$. Narita for their diligence in setting up and performing the experiments.

\section{REFERENCES}

1.Hara, T., Michiue, M., Hinokidani, O., Md. Noh, M.N. and Tsuji, T.: Experimental Study on the Characteristic of Sediment Flushing by Sluice Gate. $53^{\text {rd }}$. JSCE, Chugoku Branch, pp. 125-126, 2001 (in Japanese).

2. Md. Noh, M.N., Michiue, M. and Hinokidani, O.: Sediment Flushing Technique with a Grit Chamber. XXIX IAHR Congress, Beijing, Theme D, Vol. 2, pp. 216-223, Sept. 1621, 2001.

3. Md. Noh, M.N., Michiue, M. and Hinokidani, O.: Experimental Study on Sediment Flushing through Sluice Gate for Small Reservoir. 12 ${ }^{\text {th }}$. Congress of APD-IAHR, Bangkok, Vol. 2, pp. 641-650, Nov. 12-16, 2000.

4. Tsuji, T., Michiue, M., Hinokidani, O. and Md. Noh, M.N.: Study on Sediment Flushing through Sluice Gate for a Grit Chamber. 52 ${ }^{\text {nd }}$. JSCE, Chugoku Branch, pp. 177-178, 2000 (in Japanese).

(Received October 1, 2001) 